International Journal of English Literature and Social Sciences
Vol-6, Issue-1; Jan-Feb, 2021
Journal Home Page Available: https://ijeab.com/

\title{
On the Translation of Xia Culture in Chinese Martial Arts Novels under the Background of Cultural Confidence
} based on Legends of the Condor Heroes

\author{
Shen Yiqun
}

School of Foreign Studies, Zhejiang University of Finance \& Economics Dongfang College, Hangzhou, China

Received: 25 Oct 2020; Received in revised form: 22 Dec 2020; Accepted: 06 Jan 2021; Available online: 13 Jan 2021

C2021 The Author(s). Published by Infogain Publication. This is an open access article under the CC BY license

(https://creativecommons.org/licenses/by/4.0/).

\begin{abstract}
Cultural confidence is a nation or a country's full affirmation in its culture, the active practice of its own cultural values, as well as the firm confidence in the vitality of its culture. Introducing excellent Chinese martial arts novels to the world is a manifestation of cultural confidence. The success of the English translation of Jin Yong's martial arts novel "Legends of the Condor Heroes" by Anna Holmwood in the Western market can give Chinese translators a lot of inspiration in translating Chinese martial arts novels. This article analyzes the characteristics of the jianghu terms, characters' nicknames, and KungFu names that constitute the xia culture in Chinese martial arts novels, and explores the different strategies used in Holmwood's translation for various culturally-loaded words and phrases, namely transliteration, literal translation with annotation, free translation, and creative translation. While retaining the exotic factors in the novel so that English readers can appreciate the unique charm of Chinese martial arts culture, it also appropriately ensures the readability of the novel, which is not an easy task in translating Jin Yong's work. Thus the translation provides some references for the subsequent foreign translation of Chinese martial arts novels.
\end{abstract}

Keywords-cultural confidence, martial arts novels, xia culture, translation strategies.

\section{INTRODUCTION}

Cultural confidence is a nation or a country's full affirmation, the active practice of its own cultural value, and the firm confidence in the vitality of its culture. The Chinese nation has a continuous civilization history of more than five thousand years and has created a broad and profound Chinese culture. Literature is a strong stroke in Chinese culture, and martial arts novels are an important part of Chinese literature. Letting excellent Chinese martial arts novels go abroad and into the world is a manifestation of firm cultural confidence.

In the past, martial arts novelists, represented by Jin Yong, though had a wide range of influence among Chinese readers, were hardly known in the world. Among Jin Yong's fourteen martial arts masterpieces, only three of them, namely "The Deer and the Cauldron", "The Book 
and the Sword" and "The Flying Fox of the Snowy Mountain", have published English translation versions. In addition, the circulation of the three translations was low, and the social response was limited. For example, the English translation of "The Flying Fox of the Snowy Mountain" scored only 3.7 points on Amazon; the English translation of "The Book and the Sword" was not on the shelves.

However, on February 22, 2018, the first English translation of "Legends of the Condor Heroes" (hereinafter referred to as "Legends") Vol. 1, A Hero Born, was published in the UK. Later it reprinted six more times. Amazon's reader rating (as of the time of the author's survey December 2020) is 4.4 stars, of which 5 stars account for $70 \%, 4$ stars account for $13 \%, 3$ stars account for $8 \%$, and 2 stars $5 \%$ and 1 star $4 \%$. It can be said that it is a great success for Chinese martial arts literature to enter the international market.

The first translation and publication of "Legends" in English-speaking countries has achieved initial success. Actually besides the fourteen classic martial arts novels written by Jin Yong, there are many great works by $\mathrm{Gu}$ Long, Liang Yusheng etc. Since the publication of Holmwood's translation, many scholars have studied the dazzling tricks, culturally-loaded names, and wonderful fighting scenes in the novel from the perspective of translation. These are certainly meaningful for discussion, but the author believes that from the perspective of cultural communication, there is another point that cannot be ignored, and that is the xia culture in the book. It is the essence of Chinese martial arts novels that distinguish itself from Western knight novels and chivalrous culture. Studying the reasons and strategies to the success of Holmwood's translation can provide more reference for the translation and cultural communication of Chinese martial arts novels.

\section{XIA CULTURE IN "LEGENDS OF THE CONDOR HEROES"}

Although Chinese culture is generally viewed as a composite of Confucianism, Buddhism, and Taoism traditions, there is another important component xia. Most often translated as chivalry, xia is the very heart of Cha's philosophy. (Zhang Haiyun, 2018) Chinese xia culture has a long history. As early as the Warring States Period, Han Feizi proposed that "Confucianism used literature to disrupt law, and xia used military to violate bans." Sima Qian also gave his own definition of xia in his "Biography of Ranger": in addition to master martial arts, he is truthful in speech and firm in action; his promises must be fulfilled; he will not put his body and his life first when saving other people; even done something heroic, he does not brag his ability or his virtue" (Zhang Peiheng, 1994). Liu Ruoyu (1991) summarized xia into eight aspects in the book "The Xia in China": helping others; justice; freedom; being loyal to one's confidant; being brave; being honest and trustworthy; cherishing reputation; being generous. In Jin Yong's novels, the spirit of xia is also inherited. He has repeatedly explained the xia in his heart, which is divided into three levels. The first is the relationship with strangers, for xia will do other's a favor whenever it is needed. The second is the relationship with brothers and friends, for xia will keep the loyalty among brothers and friends. The third is the relationship with his country and his people. Take Guo Xiaotian and Yang Tiexin in "Legends" as an example. Although their martial arts are not superb, their brotherhood and their selfidentity which combines their fates with the fate of the nation are enough to be called xia. Thus based on the above characteristics of the xia culture, the author attempts to analyze it from three perspectives: jianghu terminology, characters' nicknames, and names of the martial arts moves.

\subsection{Jianghu Terminology}

Yu Yingshi (1998) stated in the first sentence of "Xia and Chinese Culture", xia is a unique product of Chinese culture; jianghu as well as the martial arts novels written with it as a background, are "the unique of Chinese culture products." Therefore, in a certain sense, if one wants to understand the xia culture, he or she should first understand jianghu. Jianghu is one of the most important concepts in Jin Yong's martial arts novels. Together with words such as xia 侠, wu 武 and yi 义, they constitute the value and meaning of Chinese martial arts novels. The 
meaning of jianghu can be interpreted in two ways, literal meaning and concept meaning. It literally means rivers and lakes, in particular the three rivers and five lakes in China. After the Eastern Han Dynasty, it generally refers to the entire Yangtze River basin. Yet it also signifies an ideal world, free from the control of the regime, such as Fan Zhongyan's famous saying "If you live in the temple, you worry about the people, and you are far away in jianghu, you worry about the king."

Jianghu in Jin Yong's novels is far away from the regime and court, and has political independence and rebellion. There are no obvious geographical divisions. The composition includes not only famous sects in martial arts, but also underworld gangs, religious groups, escorts, lone rangers, etc., and there is a set of internal values and ethical standards, which are called "rules of jianghu". Under these rules of order, the martial arts masters in "Legends" attach importance to reputation, match their behavior with their words and they do, and not bully the small and the weak. It can be said that jianghu provides a stage for those masters to show, and supports the value and meaning of martial arts novels.

\subsection{Characters' Nicknames}

The translation of the names in Holmwood's translation of "Legends" has been discussed by many. This article mainly discusses the nicknames of these martial arts masters. The nickname, also known as the titles, is based on a person's appearance, personality, occupation, specialty or living environment. It not only has the general referential function, but can also shape the character, portray the image of the character, convey emotion, and enhance the artistic expression of language.

The first volume of "Legends" translated by Anna Holmwood has 20 character nicknames. Among them, “马 王神” and “南山樵子” show the professional characteristics of the characters, “飞天蝙蝠”, “越女剑”, “断魂刀”, “追命枪”, “夺魂鞭” embody the character's KungFu specialty, “三头蛟”, “五指秘刀”and other reflect the physical characteristics of the character, “鬼门龙王”, “参仙老怪”, “千手人屠” and others borrowed traditional Chinese mythological images to shape the characters' personalities, and “闹事侠隐” and“笑弥陀” embody the life philosophy of being out of the world. In addition to personal nicknames, there is also a group nickname in the novel, such as “江南七怪”, “黑风双鞄”, “黄河四鬼” and so on. These nicknames not only make the characters more distinctive, but also include traditional Chinese culture, religious philosophy, etc., and become another highlight of the martial arts novels.

\subsection{Names of the KungFu Moves}

Another element of the xia culture in Chinese martial arts novels is the jaw-dropping KungFu moves. The KungFu names in Jin Yong's novels are derived partly from real martial arts, such as “揽雀尾”and“太极手”, but most of them are fictitious, such as “越女剑法”, “九阴白 骨爪” and “降龙十八掌” ”tc. These fictitious names of KungFu are also Jin Yong's ingenious fusion of the xia culture and traditional Chinese culture. The author summarizes the naming methods of these KungFu moves into four categories: literature, philosophy, medicine and religion.

Naming KungFu from a literary perspective is the most widely used method in Jin Yong's novels. The unique charm of Chinese in expression and description is vividly interpreted under Jin Yong's pen. Four-character phrases add the beauty of rhythm to these expressions. Take the first volume of "Legends" as an example. There are“白虹 惊天”, “春雷震怒”, “风卷云残”, “天外飞山”, “电照长 空”, “白露过江”, “苍鹰搏兔” etc.. Some render the effect of KungFu, and some depict the form of KungFu. The concise phrases give readers a strong sense of visibility, which is very difficult to translate.

Traditional Chinese philosophy is a collective concept encompassing many theoretical schools, such as Confucian philosophy, Taoist philosophy, I Ching thought, and the Five Elements System. All martial arts must be based on "qi" or "internal strength." Guo Jing was taught martial arts by the "Seven Immortals of the South" at first, but no matter how hard he tried, he couldn't get the essentials. In fact, he lacked the essence of "qi". Even though Cyclone Mei's martial arts was already very advanced, she still had to get some Quanzhen secrets from Ma Yu. "Qi" is actually 
the "Tao" in Taoism, and "Tao" is the origin of the world. Therefore, many names of kung fu are also related to philosophical thinking, such as "Nine Yin Skeleton Claw" and "Five Elements Fists".

The relationship between traditional Chinese medicine and martial arts is also relatively close. The martial arts masters attack the vital points of their opponents in a fight, and the medicine used when saving lives is also related to Chinese medicine. In the novel, “分筋错骨手”, “摧心 掌”,and various acupuncture techniques make readers feel the connection between the two.

Naming moves of KungFu from a religious perspective is widely used, especially Shaolin KungFu and Wudang KungFu. The concepts of Shaolin and Buddhism, Wudang and Taoism are often reflected in the novels. The most typical example is "Shaolin Arhat Stytle".

The above-analyzed jianghu terms, nicknames, and KungFu names are all concrete manifestations of xia culture in the novel. They carry specific cultural connotations and also condense the national complex in the martial arts culture, which is why Jin Yong's novels are widely loved by Chinese readers. They are the source of confidence in Chinese culture. Therefore, when translating, in addition to the literal meaning, the deep meaning of Chinese xia culture should be included. At this point, Holmwood's translation is relatively successful, so the following will focus on analyzing the strategies adopted by Holmwood's translation of the first volume of "Legends", when dealing with these xia cultural terms.

\section{THE TRANSLATION STRATEGIES OF "LEGENDS" FROM THE PERSPECTIVE OF CULTURAL CONFIDENCE}

The long-standing culture of the Chinese nation is the support for the Chinese spirit, and cultural confidence is the deeper and longer-lasting force. The world is currently undergoing unprecedented major changes. In the process of exploring the common destiny of human culture, it is necessary to tell the stories of one's own country so that the world can understand your culture more comprehensively and accurately. In order to introduce it to the world and gain the international recognition, translators should know what readers want and crave for. At this point, Anna Holmwood's translation of "Legends of the Condor Heroes" is undoubtedly successful. Studying the strategies adopted by Holmwood's translation in the cultural term of xia is just as Luo Xuanmin (2012) proposed that Chinese classics translation can borrowing the ships of Western translators to reach the hearts of the Western readers. Whether the publication of the translation is a success depends on the degree of acceptance by the target language readers.

From the principle of translation, it is not difficult to see that the translation of Holmwood's version of "Legends" mainly uses "alienation", so that readers can feel the charm of Chinese martial arts culture, and supplemented by "domestication" to enhance the readability of the English version. Through careful study of the translation, the author classifies the translation strategies into four categories: transliteration with annotation, literal translation (with annotation), free translation and creative translation. The former two try to achieve the foreignized effect and the latter two belong to the strategy of demestication.

\subsection{Transliteration with Annotation}

The jianghu terms mentioned above, such as jianghu, wulin, etc., are the unique products of the xia culture and also the essence of it. There is no complete equivalent in English. If translator rashly uses existing words in English, it will bring cultural misunderstandings to readers of the target language. As Holmwood mentioned in Appendix 1 of "A Hero Born", people used martial arts to translate 武 术 in Chinese. But in fact, there is a difference between the two. Martial arts originated in Europe during the Renaissance. It specifically refers to the tactics used by the military in combat. However, the martial arts in Chinese xia culture sometimes have nothing to do with the military. Such simple reciprocity is not conducive to the spread of Chinese xia culture. Therefore, in Holmwood's translation, she mostly adopted the strategy of transliteration of such terms. "武林" was translated as wulin, and "江湖" was translated as jianghu, and annotated in the translator's foreword and appendix. The specific meanings of wuxia 
and jianghu Holmwood described in the preface, "There is such an area in southern China, which is out of power, and the rules and order are formulated and followed by a group of men and women who have practiced martial arts for many years. They use the geographical features of the south, river "jiang" and lakes "hu" to create a concept of jianghu, and the idea of the forest of martial arts, wulin. This kind of alienation process retains the exotic flavor and unique meaning of the xia culture without affecting the reading experience of the target language readers.

Example 1: “无缘无故的来跟大师作对, 浑不把 江南武林中人放在眼里。”

Why did this fellow challenge Your Reverence to a fight? He

obviously doesn't think much of us masters of the southern wulin.

\section{Example 2: (郭靖)自愧初涉江湖, 事事易出毛病。}

He was yet to learn the subtler tricks of the jianghu.

In addition, the same tactics are used in terms of "内功" neigong, "师傅" shifu, and "武侠" wuxia. However, the author also noticed that because this type of expression appears very frequently in the novel, Holmwood still retained the free translation when doing part of the translation. For example sometimes “内功”is inner strength, “江湖豪杰”is masters of the rivers and lakes, "武 林高手" is translated as an exceptional practitioner of the martial arts, whose purpose is to reduce the difficulty of reading and improve the readability of the novel.

\subsection{Literal Translation}

The strategy of literal translation is mainly used in the translation of some literary KungFu names and character nicknames in "Legends".

The names of literary KungFu in Jin Yong's novels are mostly based on Chinese classical literary works, which have rich ideographic connotations. Some even can only be perceived rather than expressed. The author divides these names into two types: one is action type, the name contains the main action form of $\mathrm{KungFu}$; the other is descriptive type, mainly nouns, describing the form or effect of KungFu. When translating such a name with cultural connotation, the translator must not only try to preserve its cultural connotation, but also ensure the acceptance of the target language readers. Holmwood used literal translation in an effort to retain the images and actions of these KungFu names. The action types were mainly verbs, such as 壮士断腕 (the Brave Soldier Breaks Wrist）、空手夺白刃（Bare Hand Seizes Blade）、夜叉探 海 (Trident Searches the Sea by Night) etc. While descriptive types were mostly noun phrases, like 铁板桥 (Iron Bridge)、回马枪（the Returning Horse）、春雷震 怒(Deafening Spring Thunder)etc. This kind of translation preserves the original language to the greatest extent. Although some KungFu names are somewhat lengthy compared with Chinese, but they are creating scenes which allow readers of the target language to experience the unique charm of Chinese martial arts novels in KungFu naming.

For the nicknames of the characters in "Legends", Holmwood uses literal translations for the nicknames about the appearance and KungFu specialty, such as "Copper Corpse" and "Iron Corpse". The translation not only achieves linguistic equivalence of the original text but also reproduces the physical changes after the two practiced the "Nine Yin Manuel". "Flying Bat" Ke Zhenye is a blind. He relies on hearing to distinguish the position of the enemy. It is just like the bat's ability to move and fly in the dark without relying on eyes. Therefore, it is literally translated as Flying Bat, which is very suitable for $\mathrm{Ke}$ Zhenye's image. "Flying Divine Dragon" Ke Bixie's nickname is also related to his image of supporting justice and suppressing evil. Ke Bixie has few appearances in the book, but in the memory of his brother Ke Zhenye, for the reason that Hurricane Chen and Cyclone Mei killed many people in jianghu because of the Nine Yin Skeleton Claws, Ke Bixie was invited to kill the two, but was killed by them instead. Although dragon was originally synonymous to the evil in the West, with the rise and spread of Chinese culture, the image of dragon is no longer confined to the negative. The translator literally translated it as divine dragon, which not only respects the original text, but also 
fits the image of Ke Bixie: punishing evil and promoting good. As for the "Butcher of a Thousand Hands", the translator also adopts the strategy of literal translation, providing to the readers of the target language with a reading experience similar to that of the original language readers.

Compared with the foreignization effect of literal translation, the strategy of literal translation plus annotation compensates for the meaning, allowing readers of the target language to accurately understand the internal meaning and cultural background of the KungFu and weapons while keeping the exotic feeling, thereby reducing readers' reading burden. Take 铁菱 as an example: flying devilnuts, an iron projectile made in the shape of a kind of water chestnut native to China

\subsection{Free translation}

For the KungFu names related to philosophy and religion, and the rules of order and behavior habits in jianghu, the translator mainly adopts free translation for the reason of its complicated background knowledge and "cultural default".

The "韦护" in the KungFu name "韦护捧杵式" actually refers to the guardian god of Buddhism, Wei Tuotian (Sanskrit Skanda) who holds the vajra god. Wei Tuotian was originally the god of Brahmanism and was passed down after the fifth century North India, absorbed by Buddhism and became the patron saint, holding a vajra stick (grinding pestle) in his hand. By understanding the origin of the name of $\mathrm{KungFu}$, Chinese readers naturally have a sense of picture. Holmwood did not use the literal meaning when translating the pestle into stick. Instead, he expressed the meaning of "Protector Skanda Defends Evil", so that readers of the target language can also understand this. The religious meaning behind the name captures the essence of this move.

The jianghu in Jin Yong's novels has its own code of conduct and norms. People in jianghu consciously abide by it, forming another component of the xia culture. Jianghu masters always pay attention to reputation, and they can even sacrifice some personal interests for the sake of reputation; they have clear grievances, revenge, and retribution; they do what they say, but they believe in their words. Many moral ethics are in the same line with traditional Chinese ethics, but Western readers may not be able to understand them for a while, so the translator chose free translation.

Example 3: 韩宝驹与张阿生等都是酒量极宏之 人, 首先说好。

柯镇恶却道: “我们以七敌一, 胜之 不武, 道长还是另划道儿

吧。”

丘处机道: “你怎知一定能胜得了 我?”

Ryder Han and Zhang Asheng were drinkers, so they agreed. "But

this is one against seven," Ke Zhen'e contended. "It could never

be an honorable win for us. Could Elder Eternal Spring devise

another contest?"

"What makes you so sure you'll win?"

Example 4: 黄蓉一挣没能挣脱, 叫道: “不要 脸!”

沙通天到：“什么不要脸？”

黄蓉道: “大人欺侮孩子, 男人欺侮

女人!"

沙通天一愕, 他是成名的前辈, 觉 得果然是以大压小，放开

双手, 喝道: “进厅去说话。”

"Shameless brute!"

"Shameless? Who are you calling

shameless?"

"Bullying a child. A young girl!"

This hit right at Hector Sha's sense of pride; it did seem like an

uneven fight for someone of his reputation. He relaxed his grip 
somewhat. "Let's go inside and talk

instead."

“以多敌少“An outnumbered win is never an honorable win, and “以大欺小”adults vs teenagers or males vs females is an uneven fight. The free translation strategy reflects the translator's own interpretation to Jin Yong's jianghu rules, which also allows readers to more directly understand the code of conduct and principles in the Chinese xia culture, and appreciate the demeanor of these great masters.

\subsection{Creative translation}

There are also some nicknames and KungFu names in the novel that contain the content of ancient Chinese mythology or use four-character idioms to condense their meanings. If they are simply translated literally, they will give readers a sense of obscurity and complexity. The effect of free translation is also not very satisfying. Holmwood uses creative translation in these cases to reflect her personal understanding of Jin Yong's novels and her innovation in translation.

Nan Xiren(南希仁), the fourth-ranked in "Seven Immortals of the South", was translated as Woodcutter Nan the Merciful. The translator kept only his image of woodcutter, and added the characteristics of kindness and benevolence in his character, thus made the character more vivid.

Another martial arts gang "Four Ghosts of the Yellow River" is a bit comical in the novel. Although the nicknames are called "断魂刀、追命枪、夺魂鞭、丧门斧 ", which are quite intimidating, their martial arts are mediocre, and were played and defeated by Huang Rong. The translator translated their nicknames as "the strong, the bold, the valiant, the hardy". Although the semantics are quite different, this creative translation makes the irony function manifested.

\section{ANALYSIS OF THE GAINS AND LOSSES OF TRANSLATION STRATEGIES}

The recognition of the first volume a Hero Born of the English translation of "Legends of the Condor Heroes" proves that the xia culture in Jin Yong's novels has been preserved. The translator Anna Holmwood stands from the perspective of the target language readers and makes flexible use of transliteration, literal translation, annotation, free translation, and creative translation to supplement the missing cultural background to achieve the purpose of spreading Chinese martial arts culture. Facts have proved that these translation strategies are indeed effective and have won the recognition of Western readers. This is the gain.

However, due to her foreigner status, there are still mistranslations caused by false understanding of the original text, which is the loss. For example, the confusion between the two concepts of wulin and jianghu. The martial arts novelist $\mathrm{Xu}$ Haofeng once explained wulin in an interview: people in wulin belong to a higher social status class. They are virtuous people among the residents, living in an orderly environment. As mentioned above, jianghu has no specific geographical boundaries and compositional boundaries. There are noble and decent people, three religions and nine ranks. Therefore, when translating $\mathrm{Mu} \mathrm{Yi}$ and $\mathrm{Mu}$ Nianci's fight for marriage, Yang Kang's entourage said, “怎会跟你这等走江湖买解 的低三下四之人攀亲”, Holmwood translated as “that our master would marry a wretched girl of the wulin". This is a misuse of wulin for jianghu.

Another example is the KungFu name "二郎担山 Erlang Danshan". Erlang refers to the god Yang Jian. Legend goes that in ancient times, there were ten suns in the sky, so that the crops could not grow, and the people were miserable. Seeing this scene, the god Yang Jian decided to transport the soil on the mountain with a pole to suppress the sun so that it could not rise. He carried a total of nine mountains and finally allowed the people to grow crops. Jin Yong chose this mythological story to describe martial arts, highlight Chinese culture, and also bring a sense of picture to the Chinese readers. However, the term "Erlang Danshan" appears in intense fighting scenes in the novel. If you choose a literal translation or annotated strategy, it will destroy the rhythm of the entire scene. Therefore, Holmwood adopted a free translation, but his translation "Gentleman's Cape" could not reflect the spirit of Erlang's devotion. The word Cape has nothing to do with poles and 
movements, which may be caused by the translator's lack of understanding of the mythological character.

As for the reason why Holmwood adopted the above translation strategies, the author believes that the main purpose are as follows. First, promoting Chinese culture, especially the xia culture. Jin Yong's novels are so popular in China. Although the translator is a foreigner, she is full of confidence in Chinese culture and focuses on introducing these cultures to Western readers without harming the spirit of Chinese culture. Second, enhancing readability and improving the efficiency of cross-cultural communication. Jin Yong's novels have not been able welcomed in the international market before. The New York Review of Books argued that the novel is "too foreign and too Chinese". Holmwood uses free translation and creative translation, especially the difficult translation of KungFu names and character names, and deletes some fragments with complex historical background, so that readers can understand the cultural meaning without reading a lot of notes. This is worthwhile Chinese translators to learn from.

\section{CONCLUSION}

As the representative of Chinese martial arts novels, Jin Yong's novels contain strong cultural characteristics. As a foreign translator, Anna Holmwood is able to have confidence in Chinese culture and spread the xia culture in Chinese martial arts novels to Western readers. Facts have proved that such a practice is feasible. Chinese scholars and translators should strengthen cultural self-confidence, promote the spread of Chinese culture to the outside world, and realize the harmonious dialogue between Chinese and Western cultures.

\section{REFERENCES}

[1] Jin Yong. Legends of the Condor Heroes 1: A Hero Born $[\mathrm{M}]$. tr. Anna Holmwood London: MacLehose Press, 2018.

[2] Liu Ruoyu. Chinese Knight-errant.[M]. Shanghai: SDX Joint Publishing Company, 1991.

[3] Luo Xuanming, Yang Wendi. "Cultural Awareness and Chinese Classics Translation" [J]. Foreign Languages and Their Teaching. 2012. Vol. 5. p63-66.

[4] Xu Jianlou. "Chinese Chivalry and Western Knight Spirit" [J]. Journal of Huangshan University. Vol.8, No. 2 Apr. 2006, p65-68.

[5] Yu Yingshi. "Xia and Chinese Culture", Liu Shaoming, Chen Yongming eds. Papers on Martial Arts Fictions. [A]. Hong Kong: Mingheshe, 1998.

[6] Zhang Haiyun, "The Literary Legacy of Louis Cha" Sixth Tone, https://www.sixthtone.com/news/1003139/the-literar y-legacy-of-louis-cha, 2018.

[7] Zhang Peiheng. "A Historic Study of Chinese Xia Culture: from Youxia to Wuxia" $[\mathrm{J}]$. Fudan University Journal. 1994 Vol. 3. p75-82. 